\title{
Effect of Menopause on Quality of Life and Psychological Profile of Women in Gorgan, Iran
}

\author{
Soheyla Kalantari ${ }^{1}$, Fatemeh Heidari Lahsheri ${ }^{2}{ }^{*}$ Ramazan Hassanzadeh $^{2}$ \\ ${ }^{1}$ Department of Surgical Technology, School of Paramedical Sciences, Golestan University of Medical \\ Sciences, Gorgan, Iran ${ }^{2}$ Department of Psychology, Sari Branch, Islamic Azad University, Sari, Iran
}

\begin{abstract}
Introduction: Menopause is an important event accompanied with significant hormonal changes that have permanent and irreversible effects on women's lives. The purpose of this study was to compare the quality of life and psychological profile of postmenopausal and non-menopausal women in Gorgan, Iran. Materials and Methods: This descriptive-analytical study was conducted on 120 women (60 non-menopausal and 60 postmenopausal women) who were selected via randomized sampling. Data were collected using a quality of life questionnaire and the Minnesota multifaceted questionnaire. Descriptive and analytical statistics were used to analyze the data. Results: The mean age of postmenopausal women and non-menopausal women was $56.53 \pm 1.32$ years and $57.43 \pm 1.02$ years, respectively. The vasomotor and physical function and psychological profile of postmenopausal and non-menopausal women were significantly different $(\mathrm{P}<0.05)$. Education had no effect on the quality of life and the psychological profile of postmenopausal and non-menopausal women $(\mathrm{P}<0.05)$. Conclusions: The present study showed that common menopausal symptoms affect the quality of life and psychological profile of postmenopausal women. Relieving symptoms of menopause can promote quality of life of postmenopausal women and prevent complications and adverse psychological effects of menopause in these individuals.
\end{abstract}

KEYWORDS: Menopause, Quality of life, Psychological profile

*Correspondence: Dr. Ramazan Hassanzadeh, Address: Department of Psychology, Sari Branch, Islamic Azad University, Sari, Iran, Telephone: +989113232106, Email: rhassanzadehd@yahoo.com

\section{INTRODUCTION}

Menopause is an important event accompanied with significant hormonal changes that have permanent and irreversible effects on women's lives [1]. Ovulation cycle and production of estradiol and progesterone decline a few years before menopause. Menopause occurs when the remaining follicles become resistant to increased level of follicle-stimulating hormone [2]. Symptoms of menopause include physical, psychological and sexual complaints. Physical symptoms include hot flushes, vaginal mucosal atrophy and irritable bladder, palpitation, headache and muscle pain. Psychological symptoms include irritability, anger and depression. Sexual symptoms include decreased sexual drive or sexual satisfaction [3-5]. Although menopause is a normal biological process in women, it is not defined nor experienced in the same manner in all women. In fact, the mental-psychological state and emotional, cultural and social health of an individual may affect this experience [2].
In a systematic review of prospective studies, Ayers et al. showed that women who had a more negative attitude toward menopause in the premenopausal period experienced more severe hot flashes [6]. Duration, severity and impact of menopausal symptoms may vary from person to person and from society to society. Some women experience severe symptoms that affect their physical and social performance as well as their quality of life [7], which is a subjective component of well-being and one of the health indices [8].

In a systematic review by Bahri et al. (2016), about half of the women had a neutral attitude toward menopause [9]. In a cross-sectional study by Nowroozi et al. (2013), there was a positive and significant correlation between attitude toward menopause and quality of life, which also had a significant correlation with knowledge about menopause [10]. Various studies in Iran and other parts of the world have shown the negative and positive 
impact of menopause on the quality of life of postmenopausal women $[4,11,12]$. In addition, the physical and mental health of women declines a year after menopause compared to the premenopausal state [13]. The physical and psychological signs and symptoms can also lower women's quality of life [14]. Therefore, studying the quality of life and psychological profile can help clarify the problems and complications of menopause, the severity of their impact and the aspects of life affected by these complications. It also identifies the educational, therapeutic and counseling needs for establishment and implementation of healthcare plans and policies. The results of such studies are effective in promoting women's health, helping them maintain physical and mental health during middle age and in the following years. Considering the importance of information on screening planning as well as prevention and reduction of the complications associated with menopause, this study aimed to assess the quality of life and psychological profile of postmenopausal and non-menopausal women in the city of Gorgan, Iran.

\section{MATERIAL AND METHODS}

This descriptive-analytical study was carried out on 60 postmenopausal and 60 non-menopausal randomly selected women in Gorgan (Iran) in 2016. The study received approval from the ethics committee of Islamic Azad University of Sari and informed consent was obtained from all participants.

Inclusion criteria included willingness to participate in the study, self-reported physiological menopause, confirmation of menopause by a gynecologist and no history of surgery in the past three months. Exclusion criteria included having diseases including diabetes, hypertension and thyroid, liver and kidney disease, history of cancer or heart attack or stroke, loss of a close relative in the past six months, consumption of neuropsychiatric drugs, unwillingness to participate or continue participating in the study. Prior to participation in the study, details regarding the purpose, benefits and anticipated results of the research were explained for the subjects and they were assured of the confidentially of information collected in the study. A questionnaire was then completed in the presence of the researcher during four-person sessions. Sample size was determined based on both variables of menopausal symptoms and quality of life. Demographic information including age, age at menopause, number of children and education level were collected using a questionnaire. The menopause-specific quality of life (MENQOL) questionnaire was used for assessment of quality of life in postmenopausal women. The questionnaire consists of 29 questions in four domains: vasomotor, psychomotor, physical and sexual dysfunction. The answers were scored from 1 to 7 (1: not at all, 7: very much). Validity and reliability of the questionnaire have been assessed in other studies with a correlation coefficient of 0.95 .

The Minnesota multiphasic personality inventory (MMPI) included 71 questions on the psychological state of the subjects with three validity scales (L, F, K) and eight clinical subscales including hypochondriasis, depression, hysteria, psychopathic deviate, paranoia, psychasthenia, schizophrenia and hypomania [16]. Reliability of the whole test was confirmed by the Cronbach's alpha coefficient of $0.91(\mathrm{P}<0.001)$ [17].

After completion of the questionnaire, data were analyzed in SPSS 16 using descriptive statistics with central indices and inferential statistics. T-test was used to compare the two independent groups. A P-value of less than 0.05 was considered statistically significant.

\section{RESULTS}

The mean age of subjects in the menopause group was $56.53 \pm 1.32$ years (range 38-49 years) and the mean age of non-menopausal women was $57.43 \pm 1.02$ years. In addition, 
$57.5 \%$ of the subjects had a single child and $42.5 \%$ had a bachelor's degree. Significant difference were observed in the mean scores of quality of life in terms of the vasomotor and physical function between the postmenopausal and non-menopausal women $(\mathrm{P}<0.05)$. However, the two groups had no significant difference in terms of psychosocial and sexual domains $(\mathrm{P}>0.05)$. The mean scores of psychological profile in both postmenopausal and non-menopausal groups were significantly different $(\mathrm{P}<0.05)$ (Table 1).

Table 1. Difference between the mean scores of quality of life and the scores of psychological profile in postmenopausal and non-menopausal women

\begin{tabular}{|c|c|c|c|c|c|c|}
\hline Clinical scales & Group & $\begin{array}{l}\text { Mean } \\
\text { score }\end{array}$ & $\begin{array}{l}\text { Standard } \\
\text { deviation }\end{array}$ & $\mathbf{t}$ & df & P-value* \\
\hline \multirow[t]{2}{*}{ Vasomotor } & Postmenopausal & 2.022 & 0.878 & \multirow[t]{2}{*}{8.172} & \multirow[t]{2}{*}{118} & \multirow[t]{2}{*}{0.001} \\
\hline & Non-menopausal & 1.061 & 0.241 & & & \\
\hline \multirow[t]{2}{*}{ Psychosocial } & Postmenopausal & 1.557 & 0.909 & \multirow[t]{2}{*}{0.523} & \multirow[t]{2}{*}{118} & \multirow[t]{2}{*}{0.602} \\
\hline & Non-menopausal & 1.476 & 0.782 & & & \\
\hline \multirow[t]{2}{*}{ Physical } & Postmenopausal & 1.827 & 1.061 & \multirow[t]{2}{*}{2.422} & \multirow[t]{2}{*}{118} & \multirow[t]{2}{*}{0.017} \\
\hline & Non-menopausal & 1.472 & 0.394 & & & \\
\hline \multirow[t]{2}{*}{ Sexual } & Postmenopausal & 2.033 & 1.376 & \multirow[t]{2}{*}{1.317} & \multirow[t]{2}{*}{118} & \multirow[t]{2}{*}{0.190} \\
\hline & Non-menopausal & 1.750 & 0.940 & & & \\
\hline \multirow[t]{2}{*}{ Hypochondriasis } & Postmenopausal & 0.510 & 0.048 & \multirow[t]{2}{*}{14.177} & \multirow[t]{2}{*}{117} & \multirow[t]{2}{*}{0.001} \\
\hline & Non-menopausal & 0.395 & 0.039 & & & \\
\hline \multirow[t]{2}{*}{ Depression } & Postmenopausal & 0.235 & 0.082 & \multirow[t]{2}{*}{8.249} & \multirow[t]{2}{*}{118} & \multirow[t]{2}{*}{0.001} \\
\hline & Non-menopausal & 0.129 & 0.056 & & & \\
\hline \multirow[t]{2}{*}{ Hysteria } & Postmenopausal & 0.455 & 0.058 & \multirow[t]{2}{*}{17.450} & \multirow[t]{2}{*}{118} & \multirow[t]{2}{*}{0.001} \\
\hline & Non-menopausal & 0.279 & 0.051 & & & \\
\hline \multirow{2}{*}{$\begin{array}{l}\text { Psychopathic } \\
\text { Deviate }\end{array}$} & Postmenopausal & 0.230 & 0.062 & \multirow[t]{2}{*}{10.572} & \multirow[t]{2}{*}{118} & \multirow[t]{2}{*}{0.001} \\
\hline & Non-menopausal & 0.126 & 0.044 & & & \\
\hline \multirow[t]{2}{*}{ Paranoia } & Postmenopausal & 0.181 & 0.106 & -3.003 & 117 & 0.001 \\
\hline & Non-menopausal & 0.248 & 0.135 & & & \\
\hline Psychasthenia & Postmenopausal & 0.275 & 0.075 & 6.978 & 118 & 0.001 \\
\hline & Non-menopausal & 0.158 & 0.105 & & & \\
\hline Schizophrenia & Postmenopausal & 0.230 & 0.070 & 5.252 & 117 & 0.001 \\
\hline & Non-menopausal & 0.171 & 0.049 & & & \\
\hline Hypomania & Postmenopausal & 0.468 & 0.468 & 11.476 & 118 & 0.001 \\
\hline & Non-menopausal & 0.371 & 0.371 & & & \\
\hline
\end{tabular}

*Independent t-test

There was no significant difference in the mean scores of quality of life domains between the postmenopausal and nonmenopausal women considering the education level (Table 2).

Table 2. Quality of life of postmenopausal and non-menopausal women based on their education

\begin{tabular}{|c|c|c|c|c|c|c|c|}
\hline \multicolumn{8}{|c|}{ level } \\
\hline Group & Variable & & $\begin{array}{l}\text { Sum of } \\
\text { squares }\end{array}$ & df & $\begin{array}{c}\text { Mean } \\
\text { squares }\end{array}$ & F-value & $\begin{array}{c}\text { P- } \\
\text { value* }\end{array}$ \\
\hline \multirow[t]{3}{*}{ Postmenopausal } & \multirow{6}{*}{ Vasomotor } & Intragroup & 3.351 & 4 & 0.838 & \multirow[t]{3}{*}{1.092} & \multirow[t]{3}{*}{0.369} \\
\hline & & Intergroup & 42.175 & 55 & 0.767 & & \\
\hline & & Total & 45.526 & 59 & & & \\
\hline \multirow{3}{*}{ Non-menopausal } & & Intragroup & 0.105 & 2 & 0.052 & \multirow{3}{*}{0.869} & \multirow[t]{3}{*}{0.414} \\
\hline & & Intergroup & 3.338 & 57 & 0.059 & & \\
\hline & & Total & 3.443 & 59 & & & \\
\hline \multirow[t]{2}{*}{ Postmenopausal } & & Intragroup & 3.295 & 4 & 0.824 & \multirow[t]{2}{*}{0.995} & \multirow[t]{2}{*}{0.418} \\
\hline & & Intergroup & 45.550 & 55 & 0.828 & & \\
\hline
\end{tabular}




\begin{tabular}{|c|c|c|c|c|c|c|c|}
\hline & Psychosocial & Total & 48.845 & 59 & & & \\
\hline \multirow[t]{3}{*}{ Non-menopausal } & & Intragroup & 1.675 & 2 & 0.838 & \multirow[t]{3}{*}{0.519} & \multirow[t]{3}{*}{0.722} \\
\hline & & Intergroup & 34.434 & 57 & 0.604 & & \\
\hline & & Total & 36.109 & 59 & & & \\
\hline \multirow[t]{3}{*}{ Postmenopausal } & \multirow{6}{*}{ Physical } & Intragroup & 2.419 & 4 & 0.605 & \multirow[t]{3}{*}{2.762} & \multirow[t]{3}{*}{0.072} \\
\hline & & Intergroup & 64.060 & 55 & 1.165 & & \\
\hline & & Total & 66.479 & 59 & & & \\
\hline \multirow[t]{3}{*}{ Non-menopausal } & & Intragroup & 0.816 & 2 & 0.406 & \multirow[t]{3}{*}{1.036} & \multirow[t]{3}{*}{0.397} \\
\hline & & Intergroup & 8.386 & 57 & 0.147 & & \\
\hline & & Total & 9.198 & 59 & & & \\
\hline \multirow[t]{3}{*}{ Postmenopausal } & \multirow{6}{*}{ Sexual } & Intragroup & 7.826 & 4 & 1.957 & \multirow[t]{3}{*}{1.036} & \multirow[t]{3}{*}{0.397} \\
\hline & & Intergroup & 103.885 & 55 & 1.889 & & \\
\hline & & Total & 111.711 & 59 & & & \\
\hline \multirow[t]{3}{*}{ Non-menopausal } & & Intragroup & 5.631 & 2 & 2.815 & \multirow[t]{3}{*}{3.451} & \multirow[t]{3}{*}{0.038} \\
\hline & & Intergroup & 46.508 & 57 & 0.816 & & \\
\hline & & Total & 52.139 & 59 & & & \\
\hline
\end{tabular}

*ANOVA

There was no statistically significant difference between the psychological menopausal women based on the education profile of postmenopausal and nonlevel $(\mathrm{P}<0.05)$ (Table 3).

Table 3. Psychological profile of postmenopausal and non-menopausal women in Gorgan based on the education level

\begin{tabular}{|c|c|c|c|c|c|c|c|}
\hline Group & Variable & & $\begin{array}{l}\text { Sum of } \\
\text { squares }\end{array}$ & df & $\begin{array}{c}\text { Mean } \\
\text { squares }\end{array}$ & F-value & $\begin{array}{c}\text { P- } \\
\text { value* }\end{array}$ \\
\hline \multirow{3}{*}{ Postmenopausal } & \multirow{6}{*}{ Hypochondriasis } & Intragroup & 0.009 & 4 & 0.002 & \multirow{3}{*}{0.869} & \multirow{3}{*}{0.472} \\
\hline & & Intergroup & 0.133 & 55 & 0.002 & & \\
\hline & & Total & 0.142 & 59 & & & \\
\hline \multirow{3}{*}{$\begin{array}{c}\text { Non- } \\
\text { menopausal }\end{array}$} & & Intragroup & 0.005 & 2 & 0.002 & \multirow[t]{3}{*}{1.559} & \multirow[t]{3}{*}{0.219} \\
\hline & & Intergroup & 0.084 & 56 & 0.001 & & \\
\hline & & Total & 0.088 & 58 & & & \\
\hline \multirow[t]{3}{*}{ Postmenopausal } & \multirow[t]{6}{*}{ Depression } & Intragroup & 0.020 & 4 & 0.005 & \multirow[t]{3}{*}{0.729} & \multirow[t]{3}{*}{0.576} \\
\hline & & Intergroup & 0.380 & 55 & 0.007 & & \\
\hline & & Total & 0.4000 & 59 & & & \\
\hline \multirow{3}{*}{$\begin{array}{c}\text { Non- } \\
\text { menopausal }\end{array}$} & & Intragroup & 0.004 & 2 & 0.002 & \multirow[t]{3}{*}{0.662} & \multirow[t]{3}{*}{0.520} \\
\hline & & Intergroup & 0.187 & 57 & 0.003 & & \\
\hline & & Total & 0.191 & 59 & & & \\
\hline \multirow[t]{3}{*}{ Postmenopausal } & \multirow[t]{6}{*}{ Hysteria } & Intragroup & 0.024 & 4 & 0.006 & \multirow[t]{3}{*}{1.817} & \multirow[t]{3}{*}{0.139} \\
\hline & & Intergroup & 0.181 & 55 & 0.003 & & \\
\hline & & Total & 0.204 & 59 & & & \\
\hline \multirow{3}{*}{$\begin{array}{c}\text { Non- } \\
\text { menopausal }\end{array}$} & & Intragroup & 0.006 & 2 & 0.003 & \multirow[t]{3}{*}{1.065} & \multirow[t]{3}{*}{0.352} \\
\hline & & Intergroup & 0.152 & 57 & 0.003 & & \\
\hline & & Total & 0.157 & 59 & & & \\
\hline \multirow[t]{3}{*}{ Postmenopausal } & \multirow{6}{*}{$\begin{array}{c}\text { Psychopathic } \\
\text { Deviate }\end{array}$} & Intragroup & 0.017 & 4 & 0.004 & \multirow[t]{3}{*}{1.136} & \multirow[t]{3}{*}{0.349} \\
\hline & & Intergroup & 0.210 & 55 & 0.004 & & \\
\hline & & Total & 0.228 & 59 & & & \\
\hline \multirow{3}{*}{$\begin{array}{c}\text { Non- } \\
\text { menopausal }\end{array}$} & & Intragroup & 0.011 & 2 & 0.005 & \multirow[t]{3}{*}{2.809} & \multirow[t]{3}{*}{0.069} \\
\hline & & Intergroup & 0.107 & 57 & 0.002 & & \\
\hline & & Total & 0.117 & 59 & & & \\
\hline \multirow[t]{3}{*}{ Postmenopausal } & \multirow[t]{3}{*}{ Paranoia } & Intragroup & 0.026 & 4 & 0.007 & \multirow[t]{3}{*}{0.564} & 0.690 \\
\hline & & Intergroup & 0.630 & 55 & 0.012 & & \\
\hline & & Total & 0.656 & 59 & & & \\
\hline
\end{tabular}




\begin{tabular}{|c|c|c|c|c|c|c|c|}
\hline \multirow{3}{*}{$\begin{array}{c}\text { Non- } \\
\text { menopausal }\end{array}$} & & Intragroup & 0.077 & 2 & 0.039 & \multirow[t]{3}{*}{2.182} & \multirow[t]{3}{*}{0.122} \\
\hline & & Intergroup & 1.009 & 57 & 0.018 & & \\
\hline & & Total & 1.087 & 59 & & & \\
\hline \multirow[t]{3}{*}{ Postmenopausal } & \multirow[t]{6}{*}{ Psychasthenia } & Intragroup & 0.018 & 4 & 0.005 & \multirow[t]{3}{*}{0.788} & \multirow[t]{3}{*}{0.538} \\
\hline & & Intergroup & 0.319 & 55 & 0.006 & & \\
\hline & & Total & 0.338 & 59 & & & \\
\hline \multirow{3}{*}{$\begin{array}{c}\text { Non- } \\
\text { menopausal }\end{array}$} & & Intragroup & 0.048 & 2 & 0.024 & \multirow[t]{3}{*}{2.258} & \multirow[t]{3}{*}{0.114} \\
\hline & & Intergroup & 0.604 & 2 & 0.011 & & \\
\hline & & Total & 0.652 & 59 & & & \\
\hline \multirow[t]{3}{*}{ Postmenopausal } & \multirow[t]{6}{*}{ Schizophrenia } & Intragroup & 0.010 & 4 & 0.002 & \multirow[t]{3}{*}{0.466} & \multirow[t]{3}{*}{0.760} \\
\hline & & Intergroup & 0.280 & 54 & 0.005 & & \\
\hline & & Total & 0.290 & 58 & & & \\
\hline \multirow{3}{*}{$\begin{array}{c}\text { Non- } \\
\text { menopausal }\end{array}$} & & Intragroup & 0.001 & 2 & 0.0001 & \multirow[t]{3}{*}{0.180} & \multirow[t]{3}{*}{0.836} \\
\hline & & Intergroup & 0.146 & 57 & 0.003 & & \\
\hline & & Total & 0.147 & 59 & & & \\
\hline \multirow[t]{3}{*}{ Postmenopausal } & \multirow[t]{6}{*}{ Hypomania } & Intragroup & 0.015 & 4 & 0.004 & \multirow[t]{3}{*}{1.358} & \multirow[t]{3}{*}{0.261} \\
\hline & & Intergroup & 0.147 & 54 & 0.003 & & \\
\hline & & Total & 0.162 & 58 & & & \\
\hline \multirow{3}{*}{$\begin{array}{c}\text { Non- } \\
\text { menopausal }\end{array}$} & & Intragroup & 0.001 & 2 & 0.0001 & \multirow[t]{3}{*}{0.218} & \multirow[t]{3}{*}{0.805} \\
\hline & & Intergroup & 0.087 & 57 & 0.002 & & \\
\hline & & Total & 0.087 & 59 & & & \\
\hline
\end{tabular}

*ANOVA

\section{DISCUSSION}

The findings of this study showed that there were significant differences between the mean scores of quality of life of postmenopausal and non-menopausal women in terms of the physical and vasomotor domains. In addition, education had no significant impact on the quality of life of the subjects. In 2010, Borimnejad et al. showed that quality of life, especially its psychosocial domain, is low in women who undergone hysterectomy before menopause [18]. Lorenzi et al. stated that women had a higher quality of life before menopause [19]. On the other hand, Yeo [20] and Satoh et al. [21] found no difference in the quality of life of postmenopausal and nonmenopausal women. Shobeiri et al., Ceylan et al. and Ghazanfarpour et al. also reported that occurrence of menopause symptoms lowers the quality of life of women. They also claimed that women with university degrees achieved a lower quality of life score, which was associated with vasomotor, psychological and physical symptoms [22,24]. In addition, Fallahzadeh found that menopause had a negative impact on the quality of life of women, and the level of university education, number of children, employment status and body mass index were associated with improved quality of life of postmenopausal women [16]. Overall, the above studies show that the quality of life of postmenopausal and non-menopausal women is different in many aspects. Our results also showed that the quality of life of postmenopausal and none-menopausal women is significantly different in some domains. Therefore, particular attention should be given to these domains when planning strategies to improve quality of life during menopause and reduce some of the shortcomings that arise during this period. Other findings of the present study indicated significant differences between all domains of the psychological profile of postmenopausal and non-menopausal women in Gorgan. Moreover, psychological disorders were observed in all psychosocial profile subscales of postmenopausal women. Georgakis et al. conducted a systematic review on the duration of menopause and menopause-associated depression and reported an inverse relationship between 
depression, age and duration of fertility. In addition, menopause at the age of $\geq 40$ years was associated with reduced risk of depression compared with early menopause [25]. In study of Chou et al., symptoms of depression were observed during the climacteric periodic [26]. On the other hand, Zang et al. claimed that rural women do not experience any symptoms of depression, and reported a relationship between depression and vasomotor symptoms and sleep disorders [27]. Afghari et al. showed that postmenopausal women experience numerous emotionalpsychological changes, which are mostly associated with feeling old [28]. Shouhani et al. stated that postmenopausal women had mild depression (32\%), mild anxiety $(22.7 \%)$ and memory impairment $(39.3 \%)$ [29]. Reed and Yen identified high body mass index, education level, parity, race and number of children as factors effective on depression during menopause. All of the above studies as well as the present study confirm the increase in psychological symptoms during menopause. The development of psychological problems in this group of individuals might be due to hormonal and physiological changes in the body. Therefore, effective planning and developing strategies on these psychological concepts and adaptation to these symptoms can help women cope with the disorders associated with menopause.[30,31]

\section{CONCLUSION}

The findings of this study show that vasomotor and physical symptoms are common among postmenopausal women, which negatively affect their quality of life. Since a considerable percentage of women at menopause already have health disorders, menopause can act as a triggering, persisting or exacerbating factor for these disorders. Thus, offering education, counseling and especial care to these individuals can facilitate improvement of the aspects of quality of life affected by menopausal symptoms.
Further studies are recommended in this regard to clarify the role of other factors effective on the quality of life including socioeconomic status and culture.

\section{ACKNOWLEDGEMENTS}

The authors would like to express their appreciation to all women who participated in this study. This article is based on the results of a Master's thesis in General Psychology.

\section{REFERENCES}

1. Danforth DN. Danforth's obstetrics and gynecology: Lippincott williams \& wilkins; 2008.

2. Burkman RT. Berek \& Novak's gynecology. JAMA. 2012;308(5):516-7.

3. Santoro N, Epperson CN, Mathews SB. Menopausal Symptoms and Their Management. Endocrinology and metabolism clinics of North America. 2015;44(3):497-515.

4. Hoga L, Rodolpho J, Goncalves B, Quirino B. Women's experience of menopause: a systematic review of qualitative evidence. JBI database of systematic reviews and implementation reports. 2015;13(8):250-337.

5. Islam MR, Gartoulla P, Bell RJ, Fradkin P, Davis SR. Prevalence of menopausal symptoms in Asian midlife women: a systematic review. Climacteric : the journal of the International Menopause Society. 2015;18(2):157-76.

6. Ayers B, Forshaw M, Hunter MS. The impact of attitudes towards the menopause on women's symptom experience: a systematic review. Maturitas. 2010;65(1):28-36.

7. Waheed K, Khanum A, Butt A, Ejaz S, Randhawa F. Quality of Life after Menopause in Pakistani Women. Gynecol Obstet (Sunnyvale). 2016;6(367):2161-0932.

8. Hakimi S, Nazarpour S, Ramezani Tehrani F, Simbar M, Zaiery F. Women's Experiences about Menopause and Related Factors. Iranian $\mathbf{J}$ Endocrinol Metab. 2017;19(3):185-93.

9. Bahri N, Latifnejad Roudsari R, Tohidinik HR, Sadeghi R. Attitudes towards menopause among Iranian women: A systematic review and metaanalysis. Iranian Red Crescent medical journal. 2016;18(10):e31012.

10. Norozi E, Mostafavi F, Hasanzadeh A, Moodi M, Sharifirad G. Factors affecting quality of life in 
postmenopausal women, Isfahan, 2011. J Edu Health Promot. 2013;2(1):1-7.

11. Li S, Ho SC, Sham A. Relationship between menopause status, attitude toward menopause, and quality of life in Chinese midlife women in Hong Kong. Menopause. 2016;23(1):67-73.

12. Haghi HB, Hakimi S, Mirghafourvand M, Mohammad-Alizadeh S, Charandabi MF. Comparison of Quality of Life Between Urban and Rural Menopause Women and its Predictors: A Population Base Study. INT J Womens Health Reprod Sci. 2017;5(2):137-42.

13.Mishra G, Kuh D. Perceived change in quality of life during the menopause. Social science \& medicine (1982). 2006;62(1):93-102.

14. Dalal PK, Agarwal M. Postmenopausal syndrome. Indian Journal of Psychiatry. 2015;57(Suppl 2):S222-S32.

15. Mohammad-Alizadeh-Charandabi S, Rezaei N, Hakimi S, Montazeri A. Predictors of health-related quality of life in postmenopausal women: a population-based study. Journal of caring sciences. 2012;1(4):201.

16. Fallahzadeh H. Quality of life after the menopause in Iran: a population study. Quality of life research : an international journal of quality of life aspects of treatment, care and rehabilitation. 2010;19(6):813-9.

17. Mohammadi Zeidi E, Pakpour A, Mohammadi Zeidi B. The impact of educational interventions based on individual empowerment model on knowledge, attitude, self-efficacy, self esteem and quality of life of postmenopausal women. Iran $\mathbf{J}$ Nurs. 2013;26(81):21-31.

18. Borimnejad L, Mohadeth Ardebili F, Jozee Kabiri F, Haghani H. Comparison of Quality of Life after Hysterectomy in Pre and Post Menopause Period in Iranian Women. Iranian J Obstet Gyn Infertil. 2011;13(6):39-45. doi: 10.22038/ijogi.2011.5801.

19. De Lorenzi DR, Saciloto B, Artico GR, Fontana SK. Quality of life and related factors among climacteric women from south Brazil. Acta medica portuguesa. 2009;22(1):51-8.

20. Yeo JH. Influencing factors on quality of life in pre-and postmenopausal women. Journal of Korean Academy of Nursing. 2004;34(7):1334-42.

21. Satoh T, Ohashi K. Quality-of-life assessment in community-dwelling, middle-aged, healthy women in Japan. Climacteric : the journal of the International Menopause Society. 2005;8(2):146-53.

22. Shobeiri F, Jenabi E, Hazavehei SMM, Roshanaei G. Quality of life in postmenopausal women in Iran: a population-based study. J menopausal Med. 2016;22(1):31-8.

23. Ceylan B, Ozerdogan N. Menopausal symptoms and quality of life in Turkish women in the climacteric period. Climacteric : the journal of the International Menopause Society. 2014;17(6):70512.

24. Ghazanfarpour M, Abdolahian S, Zare M, Shahsavari S. Association between anthropometric indices and quality of life in menopausal women. Gynecological endocrinology : the official journal of the International Society of Gynecological Endocrinology. 2013;29(10):917-20.

25. Georgakis MK, Thomopoulos TP, Diamantaras A, et al. Association of age at menopause and duration of reproductive period with depression after menopause: A systematic review and meta-analysis. JAMA Psychiatry. 2016;73(2):139-49.

26. Chou C-H, Ko H-C, Wu JY-W, Chang F-M, Tung Y-Y. Effect of previous diagnoses of depression, menopause status, vasomotor symptoms, and neuroticism on depressive symptoms among climacteric women: A 30-month follow-up. Taiwanese J Obstet Gyn. 2015;54(4):385-9.

27. Zang H, He L, Chen Y, Ge J, Yao Y. The association of depression status with menopause symptoms among rural midlife women in China. African health Sci. 2016;16(1):97-104.

28. Afghari A, Ahmad Shirvani M. Psychoemotional changes in menopause: A qualitative study. J Mazandaran Uni Med Sci. 2012;22(93):2738 .

29. Shouhani M, Rasouli F, Haji AP, Mahmoudi M. The survey of physical and mental problems of menopause women referred to liam health care centers. Iran J Nurs. 2007;2(4-5):57-65.

30. Reed SD, Ludman EJ, Newton KM, Grothaus LC, LaCroix AZ, Nekhlyudov L, et al. Depressive symptoms and menopausal burden in the midlife. Maturitas. 2009;62(3):306-10.

31. Yen JY, Yang MS, Wang MH, Lai CY, Fang MS. The associations between menopausal syndrome and depression during pre-, peri-, and postmenopausal period among Taiwanese female aborigines. Psychiatry Clin Neurosci. 2009;63(5):678-84. 